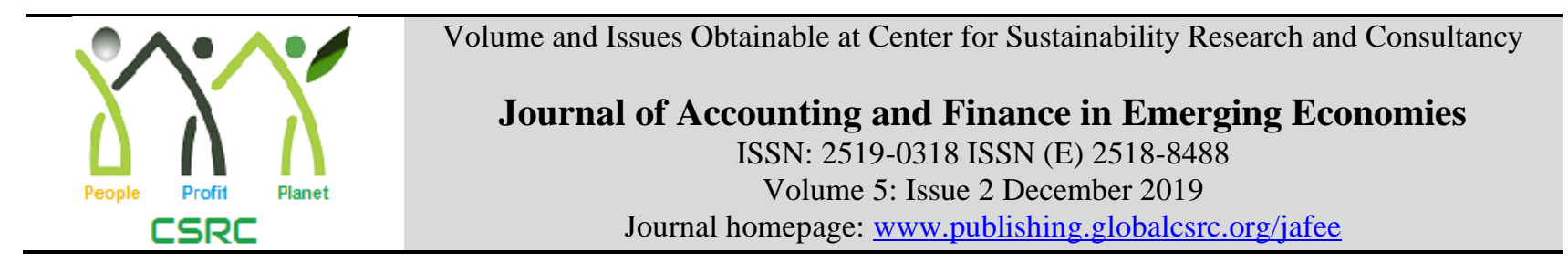

\title{
The Adoption of Management Accounting Practices (Maps) in Small and Medium Enterprises (SMEs) of Pakistan
}

\author{
${ }^{1}$ Allah Bakhsh, ${ }^{2}$ Zeeshan Mahmood, ${ }^{3}$ Sana Chaudhry \\ ${ }^{1}$ Assistant Professor, Department of Commerce, Bahauddin Zakariya University, Multan: abkhan@bzu.edu.pk \\ ${ }^{2}$ Assistant Professor, Department of Commerce, Bahauddin Zakariya University, Multan: \\ zeeshanmahmood@bzu.edu.pk. \\ ${ }^{3}$ Mphil Scholar, Department of Commerce, Bahauddin Zakariya University, Multan: sana_choudhry@ymail.com
}

\begin{tabular}{l} 
ARTICLE DETAILS \\
\hline History \\
Revised format: November 2019 \\
Available Online: December 2019
\end{tabular}

\section{Keywords}

Management Accounting

Practices( Maps), Smes, Mixed

Methodology, Textile Sector

JEL Classification:

L60, D49

\begin{abstract}
The practices of Management Accounting have not been highly adopted in developing countries. But with increased importance of these practices, firms of developing countries are motivated to adopt MAPs. In this research, MAPs align with increased importance of SMEs have been studied and provide understanding to enhance adoption of MAPs in SMEs. This study outlines the usage of MAPs in Pakistani SMEs; identify the contextual factors that affect the adoption of MAPs by SMEs and lastly explore perceived benefits and problems in adoption of these practices. A mixed methodology was used to collect data. A questionnaire with five categories of MAPs was used to examine the extent of use of MAPs by 100 SMEs of Multan from textile sector. Eight interviews were conducted to identify the factors, benefits and problems. However, the results shows that majority of respondent firms adopt traditional MAPs and other medium sized firms do more focus on contemporary MAPs. The findings of current study can be helpful and informative for practitioners and policy makers in the development of contemporary MAPs as well as provide deep insight for SMEs to enhance their business by adopting these practices.
\end{abstract}

(C) 2019 The authors, under a Creative Commons Attribution-Non Commercial 4.0

Corresponding author's email address: zeeshanmahmood@ bzu.edu.pk

Recommended citation: Bakhsh, A., Mahmood, Z. and Chaudhry, S., (2019). The Adoption of Management Accounting Practices (Maps) in Small and Medium Enterprises (Smes) of Pakistan. Journal of Accounting and Finance in Emerging Economies, 5 (2), 243-260

DOI: $10.26710 /$ jafee.v5i2.930

\section{Introduction}

Business competition has been intensified in modern business environment, both in developed and developing countries (Haron, 2013). Business owners wish to achieve higher position in market (Sleihatet al., 2012). To maximize profit and to stay competitive, management adopt best business strategies and techniques. Competitive advantages are possible when firms reduce cost of production and increase revenue. Management accountants are highly associated with the research and development of management accounting practices (MAPs). MAPs play an important role in ensuring that businesses stay competitive and profitable in the modern world (Ittner and Larcker, 
1997). MAPs are important for productivity, pricing decisions and to control cost in an organization (Johnson and Kaplan, 1987).Management Accounting Practices (MAPs) include costing practices, budgeting practices, decision support system, performance evaluation and strategic management accounting. To get success in dynamic market (Horngernet al., (2009) and to track the cost calculation and financial control manufacturing companies utilize MAPs (Uyar\&Kuzey, 2016).

In any organization management accounting is the part of its control system (Frezatti, Aguiar, Guerreiro, \&Gouvea, 2011). The role of management accounting has simply evolved from bookkeeping to increased decision making involvement (Bai \& Krishnan, 2012; Walker, Fleischman, \& Johnson, 2012). Managers use management accounting as a tool to perform their functions(Mahfar and Omar, 2004). By using these tools managers use this information especially financial information in essential way for planning, evaluating, controlling and in decisionmaking process to make competitive edge to the firms (Ashfaq et al., 2014). However, traditional management accounting much more criticized because it only focuses on internal process rather than external issues related with competition,customers value and competitive advantages.

Role of Small and Medium enterprises is of paramount importance in most of the economies of the world and they very much contribute towards servicing of their local communities and development of these countries (Devins, 1999). Aris (2007) argued that in an uncertain economy, country cannot depend much on foreign direct investment (FDI) and want to get more emphasis on SMEs as a new mechanism for generating the growth of its economy. EU defined SMEs that have valuation of balance sheet 27 million Euros and not exceeded from it and have annual turnover 40 million Euros or less from it (Schreyer, 2000). According to OECD (2000) SMEs are getting more importance because of its role in economic growth and sustainable development so, as a result SMEs entrepreneur activities increased in developing countries. SMEs also contribute in reduction of poverty and unemployment and developed domestic and export earnings.

According to Mitchell and Reid (2000) management accounting research has long been ignored the specifically in SMEs and, the topic was not considered "fashionable." Small businesses have received only limited attention in the management accounting literature (Mitchell and Reid, 2000), despite their economic importance. It is noted that inability of required use of MAPs drag SMEs towards failure. It is noted that poor management system is the cause of business failure especially in small business (Wichmann, 1983).

The SMEs get social and economic importance however there is a lack of research in this sector especially to know the use of management accounting techniques in such firms (Nandan, 2010). Some of such studies are found on management accounting practices (MAPs) in SMEs in developed countries. Drury et al. (1993) investigated MAPs in SMEs and found that SMEs use simplest techniques but large businesses use limited activity-based costing $(\mathrm{ABC})$, sensitivity analysis, and market research.

The purpose of this research study is to explore the extent of use of MAPs in SMEs, factors that determines the use of different MAPs and benefits and problems in implementing these MAPs. This research aims to fill this gap by investigating which MAPs are followed by SMEs of Multan potential benefits and challenges of implementation. Pakistan is one of the countries that emphasizes heavily on SMEs sector for generating faster growth in the national economy. Furthermore these type of studies also playing a potentially important role in informing the development of new practices that meet changing business needs for organizations (Unerman and O'Dwyer, 2010).

\section{Objectives:}

- To investigate the extent of use of management accounting practice in SMEs.

- To investigate the factors that determines the use of different MAPs in SMEs.

- To explore the benefits and problems for implementing these MAPs in SMEs.

\section{Literature Review}

\subsection{Management Accounting Practices}

Management accounting practices (MAPs) are known as the most important practices in any organization to stay competitive and sustainable. Performance evaluation as MAPs is crucial function of management accounting (Emmanuel et al., 1990). To achieve strategic objectives of organization (Jusoh and Parnell, 2008) and to provide information to managers and employees (Hall, 2008), performance evaluation is much more important. A final set of MAPs include strategic management accounting (SMA). SMA is to provide financial information analysis to the 
firm on its product markets. More recently, five dimensions of SMA usage are described by (Cadez and Guilding, 2008) are the costing; control, planning and performance measurement; strategic-decision making; competitor accounting; and customer accounting.

Several factors affect the adoption of management accounting practices. These factors mainly relate to the broader institutional and organizational environment in which the organisation operates (e.g., Hopwood \& Miller, 1994;Hopwood, 1983; and Chapman et al. 1990). These factors are part of the bigger context which must be understood for understanding accounting practices (Martin Messner, 2016). The use of MAPs is context-sensitive. Contingency theory is the dominant theoretical perspective that affects adoption of MAPs (Gerdin\&Greve, 2004). This theory explains and elaborates different factors that determine whether particular MAPs are more and less useful for particular situation of the organization (e.g., Otley, 1978; Hirst, 1981; Ezzamel, 1990; Gerdin and Greve, 2008).

The literature on extant of use of MAPs describes various settings in which firms use these practices. Messner (2016) argue that the adoption of MAPs differs as the size of organization (small or large), organization's purpose (profit or non-profit), its ownership type (private or public). Countries adopt MAPs according to environmental (political, cultural, economical) change (Hopper, 2000). The history of accounting shows that MAPs always enhance productivity and efficiency and useful in financial control and planning (Han Kang Hong, 1991).

Sulaiman et al. (2004) summarized the results of adoption of MAPs in four developing countries China, Singapore, India and Malaysia. Their result indicates that these Countries not mainly focused on contemporary management accounting practices. The probable reasons of low adoption rate is lack of expertise, lack of new techniques awareness and more importantly lack of top management support (Sulaiman et al., 2004).Lastly Frezatti (2007) investigate MAPs in medium and large companies operating in manufacturing and non-manufacturing sectors in Brazilian. The results showed that adoption of traditional practices like budgeting was more focused compared with recent management-accounting practices for example activity-based costing, balanced scorecard and economicvalue added.

\subsection{Management Accounting Practices and SMEs}

Despite considerable interest in manufacturing and other industries (Chenhall and Morries, 1986; Chenhall and Langfield, 1998, Gichaaga, 2013) relatively a few studies have been conducted on the improvement of accountability and firm performance on SMEs through MAP. Most researchers focus to study MAPs in larger firms. Only fewer studies are found to examine contingent factors of MAPs in SMEs (Ahmad \&Zabri, 2015). As organization grows up (smaller to medium or large) the use of MAPs increases. Cadez and Guilding (2008) found that strategic management accounting (SMA) usage is positively associated with company size. Burns and Scapens 2000).Bititci (2013) argue that to get sustainable and higher performance of SMEs is depicted by adoption of healthy MAPs.

\subsection{Adoption of Management Accounting Practices in SME \\ 2.3.1 Extent of Use}

Adoption rate of MAPs is as differ as the firms is more context-sensitive. Recently developed MAPs are highly adopted by larger firms in contrast to small and medium sized firms (Joshi, 2001). In India, the percentage of the extant of use of MAPs was 40 per cent. In Singapore it is noted that extant of use of MAPs is slightly low, Firms that have foreign partners use more contemporary MAPs.

\subsubsection{Factors}

Cadez and Guilding (2008) and Albu and Albu (2012) revealed that size is one of the crucial contingent factor that affect the use of MAPs. As firms growing larger they have more complex structure and operations so they highly need to adopt MAPs. Size is an explanatory factor to increased use of MAPs with the increased complexity and more decentralized decision-making. Second factor is educational background of owner, manager or decisionmaker. As much owner-manager trained and have past experience about MAPs they used MAPs in better way. The third factor that CIMA (2013) described is the nature of the firm's operations. Last factor influencing MAPs in SMEs was the diversity of business segments. When firms put eggs in different baskets they need more financial and non-financial information for decision-making. 
External stakeholder requirements are also a one of the factor that influences the use of MAPs. In MAPs literature, Hyvonen (2005) contribute by saying that in Greece, preference of variable costing is not that much popular due to the lack of external reporting and accounting restrictions. Wu, Boateng\& Drury (2007) disclose that in the adoption of MAPs ownership type also plays a vital role. It is also observed by Islam (2005) that the information and practices of MA can also be improved if firm have a clear and deep understanding about principal-agent relationships.

\subsubsection{Benefits and Problems}

One of the benefits of MA is that it provides many competitive advantages for SMEs. It is evidential that management accounting helps to provide better informative environment to create decision-making value (operational and financial decisions) and a core competitive advantage for an organization (Islam \& Kantor, 2015).

Whilst acknowledging that MAPs is under-researched in developing countries and previous researchers show that SMEs get little attention in MA research (Mitchell and Reid, 2000; Nandan, 2010. CIMA (2013) report that MA practices are not satisfactory in SMEs, and failing to leverage MA potential for helping them to achieve profitability and liquidity as financial objectives. Past literature shows that MAPs improve total quality management, financial performance and increase intensity of market competition (Ittner and Larcker, (1995); Sim and Killough, (1998);Mia and Clarke, 1999;Laitinen, (2006).

A key barrier in adoption of MAPs in SMEs is lack of communication skills (internal or external) of management. The top management do not communicate effectively with lower management in implementing the change in their organization so lower management do not accept change (Aylin Ates, 2013). Mitchell and Reid (2000) argued that the lack of management and accounting skills (partial or complete) is due to the inappropriate training in SMEs for their owner and staff. Researcher provide different reasons of widely use of traditional MAPs in developing countries (Tho et al. (1998). They explain that SMEs cannot adopt MAPs without support of top management. The most important reason of low adoption rate of MAPs in SMEs is the lack of expertise and knowledge about MAPs. Challenges occur in Malaysian SMEs and explained by National SMEs Development Council for SME Master Plan, 2012-2020 (Hamzah, 2012). Rahman (2015) describe problems in adopting MAPs in his study. The reasons are lack of access of loans to SMEs to adopt new accounting practices, limited knowledge of innovation due to the lack of training and expertise, limited adoption of new technology, lack of human resource. As a consequence, MAPs are less formalized and sophisticated in small firms than larger firms (Quinn 2011).

\section{Research Methodology}

Research methodology is the main part of any study. This research gathers empirical evidence that give an overview of "Adoption of management accounting practices in Pakistani SMEs". The research also gauges the extant of factors that contribute to the use of MAPs and benefits and problems which result from implementing MAPs. In addressing the research objectives, the data were obtained from questionnaire responses and subsequent semi-structured interviews. The questionnaires and semi-structured interviews were conducted with managerial staff of SMEs and expert personalities (i.e. trainers and consultants). Questionnaire helps to describe extent of use of MAPs in a Pakistani SME context. And semi-structured interviews sought to identify more dominant factors and benefits and problems of MAPs as advanced in the research-practice literature.

\subsection{Target population}

The target population of this study is the SMEs of Pakistan. Research questions are required to acknowledge the adoption of MAPs in Pakistan's SMEs. This study concentrates on manufacturing sector of SMEs for gathering relevant data. This study was conducted in Pakistani context and targets the manufacturing SMEs. Data were collected from the Textile sector of SMEs in Multan. The reason to select only manufacturing sectors in order to avoid distractions among different sectors. This sector highly contributes in Pakistan's economy and exports. In recognition to see this high contribution in economy and government of Pakistan aggressively support this sector. Besides its vital role in Pakistan economy, this is the most suitable sector for research to investigate MAPs as textile sector has a higher proportion of medium sized enterprises that are most likely to use MAPs.

\subsection{The questionnaire}

It is quantitative type of study and uses for descriptive purpose and empirical testing of the responses. This study used a questionnaire to explore the use of MAPs in Pakistan's SMEs which includes five sections of MA practices 
such as costing system, budgeting system, performance evaluation system, decision support system and strategic management accounting. These five sections further divided into specific type of 43 items.

\subsection{Interviews}

Interview questions are open-ended and allow interviewee to add something new that is appropriate. Interviews are semi-structured which provide potential of insight of the situations. Researcher finds many new things for further research. There is no substitute of interviews that discover important phenomenon from different situations. List of SMEs was taken from Multan Chamber of Commerce and Industry. Researchers conducted conversation with managers and accountants of the SME on MAPs. When the free-flowing conversation ceased, the protocol provided a list of open "prompt" questions.

\section{Discussion and Findings}

\subsection{Extent of the use of Management Accounting Practices}

One of the core objectives of this study is to investigate extent of use of MAPs (43 practices under 5 broad headings). The questionnaire first investigates about firm whether respondents used each practice in their firm or not. The enquiry was made to investigate 43 practices' usage by five-point Likert scale where $1=$ Never, $2=$ Rarely, 3=Occasionally, 4=Frequently and 5=Very Frequently. The following five subsections discuss further details.

\subsubsection{Costing system}

Four practices such as job costing, batch costing, contract costing and process costing are headed under the cost collection system and other three absorption costing, variable costing, absorption and variable costing and $\mathrm{ABC}$ are evaluated under costing techniques. The results surprisingly show that the respondent SMEs highly use costing system in their organizations. Table 2 shows the percentage of costing system usage in Multan SMEs of textile sector.

Table-1: Costing System

\begin{tabular}{|c|c|c|c|c|c|c|c|c|}
\hline \multicolumn{9}{|l|}{ Extent of Use } \\
\hline \multirow{2}{*}{$\begin{array}{l}\text { Costing } \\
\text { System }\end{array}$} & \multicolumn{4}{|c|}{ Cost Collection System } & \multicolumn{4}{|c|}{ Cost Techniques } \\
\hline & $\mathrm{JC}$ & $\mathrm{BC}$ & $\mathrm{CC}$ & $\mathrm{PC}$ & $\mathrm{AC}$ & $\mathrm{VC}$ & $\mathrm{AC} \& \mathrm{VC}$ & $\mathrm{ABC}$ \\
\hline Never & $3 \%$ & $2 \%$ & $11 \%$ & $0 \%$ & $2 \%$ & $2 \%$ & $3 \%$ & $31 \%$ \\
\hline Rarely & $4 \%$ & $8 \%$ & $25 \%$ & $2 \%$ & $6 \%$ & $6 \%$ & $2 \%$ & $7 \%$ \\
\hline Occasionally & $13 \%$ & $3 \%$ & $11 \%$ & $8 \%$ & $29 \%$ & $12 \%$ & $7 \%$ & $9 \%$ \\
\hline Frequently & $70 \%$ & $71 \%$ & $47 \%$ & $60 \%$ & $59 \%$ & $68 \%$ & $40 \%$ & $51 \%$ \\
\hline $\begin{array}{l}\text { Very } \\
\text { Frequently }\end{array}$ & $10 \%$ & $16 \%$ & $6 \%$ & $30 \%$ & $4 \%$ & $12 \%$ & $48 \%$ & $2 \%$ \\
\hline Total & \multicolumn{8}{|c|}{$100 \%$} \\
\hline
\end{tabular}


Table 1 shows that process costing in cost collection system is highly used in SMEs. It is observed that Medium sized firms more actively used process costing (60\% frequently and $30 \%$ very frequently). Batch costing is also significantly use in SMEs because it have positive relation with product quality. The next method that is mostly used is batch costing among respondent firms. They employed $71 \%$ batch costing frequently in their firms that is highly depend on their size of business. On the other hand, the extent of use of contract costing is relatively low and $47 \%$ used this frequently on their regular based contracts

For costing techniques, the most frequently used method in SMEs is variable costing (68\%). Absorption costing is second costing technique which is only $9 \%$ behind variable costing. The results indicate that $\mathrm{ABC}$ is not used much more in SMEs. The given percentage reflects that medium sized firms rather used ABC than smaller firms. The use of $\mathrm{ABC}$ is lower and consistent with many previous studies such as Abdel-Kader \& Luther (2008). It is also observed by past studies (Armitage \& Nicholson, (1993); Innes \& Mitchell, (1995) that the use of ABC was relatively low and only $20 \%$ firms implement this practice.

\subsubsection{Part B: Budgeting system}

In this study the use of budgeting systems was investigated as the second MAPs. Sales budget, purchase budget, production budget, cash flow budget, financial performance budget, incremental budget and zero-based budget are found under budgeting system. Table2 summarizes the results.

Table-2: Budgeting System

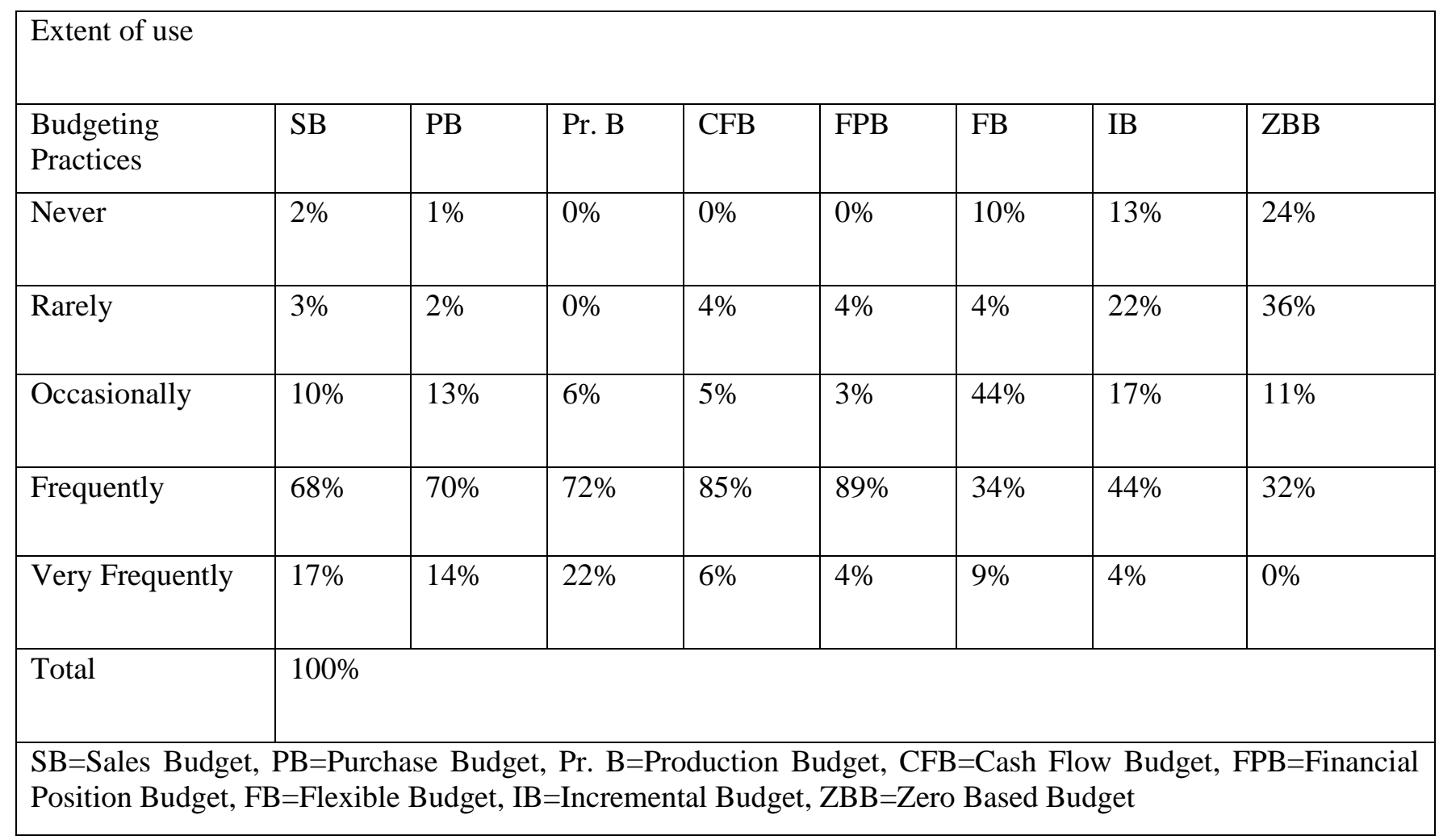

Table 2 shows that the majority of firms (respondent) highly uptake budgets in their organizations as traditional MAPs. Under the eight budgets, production budget was used much more than other budgets. Sales budget was also used frequently being adopted by respondent firms as it indicates firms raising revenue from firm's success.

Under the budgeting system it is noted that the uptake of all type of budgets are more used in medium sized firms in comparison with smaller firms. But the ZBB and incremental budget is the less implemented budgets in overall respondent firms. SMEs probably face high level of uncertainty in the mediating use of flexible budgets.

The production budget gets first rank with the highest percentage of users ( $94 \%$ frequently and very frequently). The other budgets such as sales budget, purchase budget and financial measure budgets and cash flow budgets also 
indicate high use in SMEs. When frequency of use is considered, ZBB and flexible budget are least used as of the reporting use of ZBB is $32 \%$ and flexile budget frequently used $34 \%$ of total respondent firms.

The high usage of full budgeting system is highly matched with previous studies(Shields et al. (1990); Yoshikawa (1994) and Chenhall andLangfield-Smith (1998) and Ahmad et al. (2003). Drury et al. (1993) concluded that only $42 \%$ of respondent firms in UK implement flexible budget. Szychta (2002) describes only 5\% and $28 \%$ usage of ZBB by respondent firms respectively and this usage percentage was very low.

\subsubsection{Part C: Performance Evaluation System}

Third part of the questionnaire includes two perspective financial measure and non-financial measure of performance evaluation system of the firm. The financial measures included Operating Income, Return on Investment, Variance Analysis, Sales growth, cash flow, and non-financial measures were grouped by no. of customers complaints, customers satisfaction survey, no. of warranty claims, on-time delivery, manufacturing lead time/ cycle time, defect rate, employee turnover, absentee rate. Results are shown in table 3.

Table-3: Performance Evaluation System

\begin{tabular}{|c|c|c|c|c|c|c|c|c|c|c|c|c|c|}
\hline \multicolumn{14}{|l|}{ Extent of use } \\
\hline \multirow{2}{*}{$\begin{array}{l}\text { Performance } \\
\text { evaluation } \\
\text { practices }\end{array}$} & \multicolumn{5}{|c|}{ Financial Measures } & \multicolumn{8}{|c|}{ Non-financial Measures } \\
\hline & OI & \begin{tabular}{|l} 
RO \\
I
\end{tabular} & VA & SG & $\mathrm{CF}$ & NCC & $\begin{array}{l}\mathrm{CS} \\
\mathrm{S}\end{array}$ & $\begin{array}{l}\text { NW } \\
\mathrm{C}\end{array}$ & OTD & $\begin{array}{l}\text { MLD } \\
\text { /CT }\end{array}$ & DR & ET & AR \\
\hline Never & $\begin{array}{l}0 \\
\%\end{array}$ & $9 \%$ & $0 \%$ & $0 \%$ & $0 \%$ & $6 \%$ & $\begin{array}{l}15 \\
\%\end{array}$ & $21 \%$ & $0 \%$ & $15 \%$ & $5 \%$ & $6 \%$ & $15 \%$ \\
\hline Rarely & $\begin{array}{l}0 \\
\%\end{array}$ & $2 \%$ & $0 \%$ & $0 \%$ & $2 \%$ & $15 \%$ & $4 \%$ & $16 \%$ & $9 \%$ & $8 \%$ & $10 \%$ & $38 \%$ & $32 \%$ \\
\hline Occasionally & $\begin{array}{l}7 \\
\%\end{array}$ & $\begin{array}{l}32 \\
\%\end{array}$ & $\begin{array}{l}16 \\
\%\end{array}$ & $5 \%$ & $5 \%$ & $33 \%$ & $\begin{array}{l}37 \\
\%\end{array}$ & $31 \%$ & $29 \%$ & $27 \%$ & $25 \%$ & $28 \%$ & $30 \%$ \\
\hline Frequently & $\begin{array}{l}80 \\
\%\end{array}$ & $\begin{array}{l}49 \\
\%\end{array}$ & $\begin{array}{l}66 \\
\%\end{array}$ & $\begin{array}{l}83 \\
\%\end{array}$ & $\begin{array}{l}89 \\
\%\end{array}$ & $36 \%$ & $\begin{array}{l}24 \\
\%\end{array}$ & $32 \%$ & $46 \%$ & $37 \%$ & $42 \%$ & $26 \%$ & $15 \%$ \\
\hline $\begin{array}{l}\text { Very } \\
\text { Frequently }\end{array}$ & $\begin{array}{l}13 \\
\%\end{array}$ & $8 \%$ & $\begin{array}{l}18 \\
\%\end{array}$ & $\begin{array}{l}12 \\
\%\end{array}$ & $4 \%$ & $10 \%$ & $\begin{array}{l}20 \\
\%\end{array}$ & $0 \%$ & $16 \%$ & $13 \%$ & $18 \%$ & $2 \%$ & $8 \%$ \\
\hline Total & \multicolumn{13}{|c|}{$100 \%$} \\
\hline \multicolumn{14}{|c|}{$\begin{array}{l}\text { OI=Operating Income, ROI=Return on Investment, VA=Variance Analysis, SG=Sales Growth, CF=Cash } \\
\text { Flow, NCC=No. of customers complaints, CSS=Customers satisfaction survey, NWC=No. of Warranty } \\
\text { Claims, OTD=On-Time Delivery, MLD/CT= Manufacturing Lead Time/ Cycle Time, DR=Defect Rate, } \\
\text { ET=Employee Turnover, AR=Absentee Rate }\end{array}$} \\
\hline
\end{tabular}

The results indicate that majority of firms employ performance evaluation system in their firms to acknowledge both financial and non-financial measure. This system was mostly seen in Medium sized firms. Results show that smaller firms do more emphasis on financial measure than non-financial measures due to the lack of resources. The least considered measures are warranty claims and absentee rate in performance evaluation system.

The use of financial and non-financial measures decreases from $89 \%$ to $15 \%$ respectively in case of financial and non-financial measures. Operating system is most popular financial measure in performance evaluation system and return on investment is least used measure. In non-financial measure on-time delivery (46\%) get highest percentage 
and absentee rate (15\%) get lowest percentage. In the case of warranty claims, it is evaluated that only $32 \%$ of respondents firms use warranty claims and most firms do not offer warranties.

The individual survey on customer's satisfaction does no implement because SMEs have lack of resources to adopt each and every practice of MA. The reason of low usage of customer satisfaction survey is perhaps because firms already used primary tool of customer's complaints to evaluate customer-based performance. Lastly employeebased measures such as employees' turnover and employees' absentee rates are doing not much more focused.

The results of performance evaluation system are constant with previous studies such as Phadoongsitthi (2003); Joshi (2001);Jusoh and Parnell (2008); andAbdel-Kader and Luther (2006);. With regard to non-financial performance measures previous studies conclude that firms use more on-time delivery and customers complaints measure (see for example, Chenhall and Langfield-Smith (1998); Abdel-Kader and Luther (2006); Abdel-Maksoud et al. (2008); and Phadoongsitthi (2003).The results are clearly shows that the significant number of respondents has implement performance evaluation system in their firms but they rely more on financial measures than nonfinancial measures.

\subsubsection{D: Decision support system}

Table 4 summarises the responses of extent of use of decision support system and dividing into two approaches such as short-run analysis and long-run analysis.

The results show that SMEs do not use more sophisticated approach to MA. In the short-run category PPA used more frequently in contrast to other decision support systems. The adoption of other three techniques is slightly low by respondent firms who use decision support system. Meanwhile under the long-run category, the overall uptakes are rather lower than the first category. Under the long-run category, payback technique is the leader of other decision support techniques and gets highest percentage $38 \%$ of respondent firm.

Table-4: Decision Support System

\begin{tabular}{|c|c|c|c|c|c|c|c|c|}
\hline \multicolumn{9}{|l|}{ Extent of use } \\
\hline \multirow[t]{2}{*}{ Decision Support System } & \multicolumn{4}{|c|}{ Short-run Analysis } & \multicolumn{4}{|c|}{ Long-run Analysis } \\
\hline & BEA & SCM & PPA & CPA & PB & ARR & NPV & IRR \\
\hline Never & $30 \%$ & $24 \%$ & $20 \%$ & $28 \%$ & $26 \%$ & $35 \%$ & $28 \%$ & $39 \%$ \\
\hline Rarely & $23 \%$ & $2 \%$ & $13 \%$ & $12 \%$ & $15 \%$ & $14 \%$ & $12 \%$ & $22 \%$ \\
\hline Occasionally & $15 \%$ & $42 \%$ & $17 \%$ & $32 \%$ & $21 \%$ & $37 \%$ & $21 \%$ & $30 \%$ \\
\hline Frequently & $32 \%$ & $29 \%$ & $41 \%$ & $24 \%$ & $38 \%$ & $14 \%$ & $37 \%$ & $8 \%$ \\
\hline Very Frequently & $0 \%$ & $3 \%$ & $9 \%$ & $4 \%$ & $0 \%$ & $0 \%$ & $2 \%$ & $0 \%$ \\
\hline Total & \multicolumn{8}{|l|}{$100 \%$} \\
\hline
\end{tabular}

The adoption rate of long-run analysis is very low as given importance of investment decisions in smaller firms. Results indicate that Payback technique used more in long-run analysis. Overall result shows that the capital investment techniques are not frequently used by SMEs and the results are convergent with previous studies such as Chenhall and Langfield-Smith (1998); Drury and Tayles (2006); and Joshi (2001) which reported that the usage of product profitability technique was more than $80 \%$ in respondent firms. 
Overall results depict moderate use of decision support system by SMEs and lower use of short-run analysis beyond product profitability. It is also noted that respondent firms do not highly focused on long-run decision-making techniques

\subsubsection{Part E: Strategic management accounting (SMA)}

The extent of use of SMA is analysed by six relevant variables shown in Table 5.

Table-5: Strategic Management Accounting

\begin{tabular}{|l|l|l|l|l|l|l|}
\hline Extent of use & SC & ACA & PDMS & VFPD & SCD \\
\hline $\begin{array}{l}\text { Strategic Management } \\
\text { Accounting }\end{array}$ & TC & & & & & \\
\hline Never & $22 \%$ & $49 \%$ & $42 \%$ & $30 \%$ & $25 \%$ & $29 \%$ \\
\hline Rarely & $21 \%$ & $2 \%$ & $17 \%$ & $25 \%$ & $37 \%$ & $32 \%$ \\
\hline Occasionally & $5 \%$ & $26 \%$ & $26 \%$ & $15 \%$ & $23 \%$ & $19 \%$ \\
\hline Frequently & $46 \%$ & $21 \%$ & $15 \%$ & $28 \%$ & $15 \%$ & $15 \%$ \\
\hline Very Frequently & $6 \%$ & $2 \%$ & $0 \%$ & $2 \%$ & $0 \%$ & $5 \%$ \\
\hline Total & $100 \%$ \\
\hline $\begin{array}{l}\text { TC=Target Costing, SC=Strategic Costing, ACA=Analysis the Cost of Activities, PDMS=Product } \\
\text { Development Monitoring Cost, VFPD= View Factors in Price Decision, SCD= Systematic Collection of } \\
\text { Data SC }\end{array}$ \\
\hline
\end{tabular}

Table 6 shows that the usage of strategic management accounting practices are relatively low to other practice. Small firms have a considerably lower adoption rate than medium sized firms. As noted by Ahmad (2015), SMA is an advanced MAP and more likely to employed by larger firms who will have a more sophisticated approach to strategic planning. SMEs do not SMA frequently. The number of respondents using SMA is not much higher and highest usage of target costing is $46 \%$. ACA and SCD are not popular techniques among SMEs and percentage is very low about $15 \%$ both.

Table 5 shows that strategic pricing, target costing and life cycle costing are the top three techniques used by respondents. Abdel-Kader and Luther (2006) found that just under a quarter of British firms often employed target costing.

\subsection{Factors}

The following factors affect the use of MAPs.

\subsubsection{Size of Firm}

Size is one of the factors for the use of MAPs. As noted, company size is a key factor for the adoption of management accounting in any organization (Askarany, Yazdifar, and Askary 2010).

Smaller firms have simpler accounting system. If size of firm is large and they do not implement any management accounting practices, than things going to complex. As size grows up, need of implementation of these practices also grows.

Some responses from different interviewees:

- Using management accounting practices is a well and balanced way to avoid unfavourable conditions. Maximum penetration of MAP's is necessary according to the size for the better performance of SMEs.

- Yes somehow size is very important factor to adopt MAP. Increased firms size demand change and we must have to implement new techniques and procedures to alive our firm

- Smaller firms do not focus too much on MA practices. Because they do not feel it is necessary for their simple transaction. But as things going complex it's necessary to bring change

- We have hundreds of transaction on daily bases. So to make things easy and more visible we adopt MAPs. If we do not implement MAPs than I don't think its sensible decision" (Interviewee-8) 


\subsubsection{Competition}

Competition is one of the important factors that bring change in any organization. As noted, MA system needs to analyse organizations completely and define its competitive position (Ashton et al., 1991).Some responses from interviewees are placed below:

- In the race of competition it is very satisfactory to adopt management accounting practices. I think competition is main factor that any organization make a change or adopt practices. It is a requirement to maintain organizational performance to compete others

- If we talk about factors that increase the usage of MAPs, competition is one of them. In competitive business environment, organizations must have to focus on their accounting system. It's much more necessary for survival.

- Competition is one of the factors that explain why we adopt different management accounting practices. MAPs are developed to respond to changes in the competitive environment.

- I don't think anything influence the use of new practices as competition does. Competition perceived as the most important external factor for activating managers to start work on a new system. And MAPs one of the system that used as much as competition increase.

- If you want to survive you have to compete. If you compete, you have to change. Moreover, for change you have to adopt new things. MAPs is one of the necessary thing to compete" (Interviewee-5)

\subsubsection{Organization's Structure And Environment Uncertainty}

Usage of MAPs also influenced by organization's internal financial restructuring (Laitinen 2011). Amara \&Benelifa (2017) argued that organizational structure include accounting information system of the firm, ownership structure (Lavigne, 1999), sector of activity (Dupuy, (1990) and age of firm (Ngongang, 2013) and mainly the size of firm. Major responses are given below:

- When small and simple things are going on than, no need to make hundred types of budgets. All things are simply done by an accountant or a manager. But when we start diversifying in other business segments and nature of operations and organization structure change its time to change our accounts and adopt management accounting practices. These practices help us to meet our goals.

- Growing change in business environment, economic activities and development of the accounting profession pressurise us to adopt management accounting practices.

- Diversification of business operations and ownership, and the increasing complexity of business transactions demanding us to implement management accounting practices. After implementation we are ensure about better results.

- The structure of our organization required to integrate management accounting practices. It is necessary to align things in proper way. Organization structure and content in which organization work must be match with each other. MAPs have done things in simple and appropriate way and provide an environment to operate organizations in good manner.

- MAPs help us to define capital structure of our firm. We are able to control our operations and better manage resources.

- In Pakistan we are not certain 100\% about anything. Policies and rules changed. Even prices are not determined. To sustain financial position we must adopt that type of practices that help us to pre-plan things. And as we know firms adopt MAPs to make better decisions.

\subsection{Perceived benefits}

\subsubsection{Decision Making}

Management accounting practices are important more beneficial for all organizations in different ways. One of the benefits is that it helps in planning and decision-making. Management accounting practices are the decision support system that serves the management at all levels (Grandlund and Lukka, 1998). Major responses are as under:

- To stay in touch with modern economy it is crucial to adopt and maintain management accounting practices for SMEs. These practices are helpful in decision-making process.In the access of relevant information for decision making process management accounting helps a lot.

- We use information in management accounting as a decision-making tool. Management accounting practices especially different types of budgets give a clear view to make decisions and helps to develop best business strategy. 
- In the living world, its feel necessary to compete with your competitors. Without any competition, we cannot step ahead. So to achieve our goals it's necessary to use MAPs because it gives advantage to make decision about changing trends.

- We have to face countless decisions on daily bases in business day. With the assistance of management accounting practices, it is possible for us to make best decisions. Mostly in small business we have to use this powerful tool to make our business more successful.

- If we see overall performance of our organization, Management Accounting Practices contributes a lot. It makes things simple and well mannered. It helps in decision-making process. It provides environment to management to facilitate financial decision-making. We are able to make decisions according situations and using net present value (NPV) or internal-rate-of-return (IRR). In textile sector management accounting practices are much more useful.

- In continuously changing environment we have to ensure MA is practiced in organization. A wrong decision can spoil whole organization. So it's very critical to have MAPs in firm. It is not wrong if I say it is the back bone of the firm"

\subsubsection{Accuracy of results}

MAPs are crucial and beneficial for all the organizations. One of the perceived benefits is that it provides accurate results to organization. Accurate and validate results can increase the efficiency and effectiveness of the firm. The interviewee's comments follows:

- A healthy and good record is only possible when we use the management accounting practices so that to get the exact results, in other words auditing and accounting practices must be aligned with each other"(interviewe"If the question is about the accuracy and validity of results it can only be possible after implementing Management accounting practices. With the passage of time usage of MAPs increase after seeing its perceived importance.

- I feel inspired after implementing these practices because these practices improve the efficiency of operational management by providing more insight into the results.

- We get a road map by using management accounting practices and get accurate results. The result helps us in making decisions and in continues improvement. It is a more structured way that we implement in our organization and get high scores.

- Not putting MA into practice can be harmful in result of negative outcomes. Through MAPs we can get expected results easily. It is the easy and straight forward way to get accuracy in results. After implementing these practices especially costing practices we are assure about results.

- Mostly it is noted by us that failure of firms are due to the inaccurate results. Budgets are out of control. Due to this importance of MAPs has increased more today than ever. It is the proper way that firms want to implement to sustain in competitive environment. It is the easy way to match detail performance or budgets with actual results.

\subsubsection{Organization performance}

There is a direct link in the MAPs and organization's performance. The researchers argue that business performance increase dramatically after the implementation of management accounting practices in SMEs (Hakola 2010; Laurinkeviciute and Stasiskiene 2011; Sousa et al. 2005; Zengin and Ada 2010).Comments of interviewees are given below:

- We are implementing Management Accounting practices because it increases organization performance. By using management accounting practices we make production budget on monthly and yearly bases. If we will not doing this we will not be able to judge our sales and demands.

- Performance of organization depends on the way in which organization work out. If organizations have a simple structure than I think no need to use MAPs. But if complexity of work increase than it is necessary to adopt MAPs.If we employed MAPs and strategy in alignment than we can get highest performance.

- Implementation of MAPs create a standard for organizations and defiantly effective for organization and its performance.

- No matter how the things are going on if your organization performance not increased than it's useless. For me MAPs is the tool to increase organization's performance. It is the well-mannered way to structure any organization. 
- We learn different perspectives by implementing new techniques. MA system helps us a lot to judge different things in different angles. And then we are able to make best decisions for the betterment of organization.

\subsubsection{Competitive Advantages}

It is observed that MAPs create much more competitive advantages for organization especially SMEs. It helps SMEs to compete with other large organizations. For instance, low adoption rate of MAPs can hamper global competitiveness for SMEs (Greenhalgh 2000). The interviewees say:

- For the textile sector management accounting practices makes our work easy. We have achieved the greater command on all our operations and functions of our organization through an efficient and effective approach. It contributes many competitive advantages for us.

- At the time of adopting new program such as Management Accounting Practices we deeply observed that it is very useful to survive in competitive environment. We analyse that management accounting practices change or approach daily operations and organize it in the systematic way and provide support to compete with others.

- Perceiving MAPs is fruitful in the way it reduced companies' operational expenses. If organization reduce its operational expanse, it is more beneficial for it in competitive environment. Information in management accounting is used in a proper way to make a review of cost of economic resources and help us to understand how we can spend our money in better way.

- MAPs provide a comprehensive knowledge to us related with markets, customers and products. Then we have to search new ways in order to attract our customers and get competitive advantages.

- We feel pressured more than ever in this technology-based competition. We have to find new ways to compete. Today's competitive business environment it is very tough to sustain. If you do not use latest MA system than you face tough time.

\subsection{Problems}

\subsubsection{Lack of Skills}

The key constraints in MAPs adoption is a shortage of staff that have abilities to carry out these practices. Comments of the interviewees are given below:

- Basically every organization wants to improve their performance. If they are not using these beneficial practices then there is a reason behind it. At the start of business every transaction simply recorded and no need to hire much more staff but with the passage of time as size increase we start hiring staff who are expert in management accounting practices and give training to older staff.

- When we were not implementing MAPs we have no appropriate staff, skills and knowledge about management accounting practices. The major problem is the lack of financial management skills in having proper accounting systems. If we are not able to hire new skilled staff we have to train older staff.

- Typically, we have short staff that performs accounting plus managerial practices. The same accounting staff would have to handle both financial and MA work in each enterprise. These staffs are not too much trained. To achieve highest goals we must adopt MAPs and staff that perform these practices.

- Lack of managerial and technical skills is the main obstacles that create issues in the adoption of MAPs. And create hurdle in the success of SMEs.

- Knowledge on MAPs is the basic need and I think it's not wrong if I say it is the right of the employees to learn more and more. And without training and skills firm cannot get sense of stability.

\subsubsection{Limited Resources}

A possible reason is that larger organizations have greater resources than their smaller counterparts and can, therefore, afford to adopt more sophisticated MAPs (Haldma and Laats, 2002; Al-Omiri and Drury, 2007; and Abdel-Kader and Luther, 2008). The interviewees say:

- If anyone knows the benefit of these practices and not using these than only the reseon behind it is the lack of resources.

- To identifies, measure, analyse and accumulate management accounting information, organization need resources. But if firms have limited resources then it cannot bring a change.

- As management accounting helps in to reduce the wastage of resources. But it is only possible when we have enough resources to implement MAPs" (Interviewee-6)

- It is more expensive to adopt MAPs. And training on these practices are quite insensible for smaller firms that have few resources. 


\section{Conclusions}

SMEs operate in different sectors but one of the most important sectors is textile sector. Contributions of textile sector are remarkable in Pakistan's economy in terms of GDP, investment, exports, employment and foreign exchange earnings. It contributes around $46 \%$ of the overall manufacturing activities, $35 \%$ of country's labour force and $31 \%$ of total investment is related to this sector.

Results have concluded that the management accounting practices permit SMEs to compete with competitors and reduce business failure. It is necessary to enhance knowledge on usage of MAPs among SMEs in Pakistan after evaluating above advantages. This study filled a gap by taking SMEs as a population to investigate adoption of MAPs and it is confirmed that this research helps policy makers in better decision-making. This study addresses the current state of usage of MAPs by SMEs in Pakistan. Five sub-types of MAPs identified such as costing, budgeting, performance evaluation, decision-making and Strategic management accounting. It is viewed that usage of these practices are significantly high in both small and medium sized enterprises. The usage percentage varies according to respondents. Small firms use these practices $45 \%$ to $76 \%$ and it ranges from $67 \%$ to $86 \%$ among medium sized enterprises. The results reviled that high usage of MAPs partly explained by highly qualified staff (94\%) and reasons behind low usage is less qualified staff $(68 \%)$ in small firms.

The results also shows that past MAPs such as costing, budgeting and performance evaluation are higher (76\% to $83 \%$ ) than contemporary MAPs (51\% to 63\%) such as decision support system and SMA. It is observed that larger firms concentrate more on contemporary MAPs and learn more new techniques and ideas in contrast to smaller firms.

Results revealed that medium sized enterprises use these practices more than small enterprises and SMEs use financial-based MA practices (financial budgeting, financial performance measures, and product profitability analysis). SMEs use process costing and variable costing in conventional costing system. Non-financial measures are taken as important element in SMEs and these measures relate to internal processes and are customers-oriented. It is also noted that contemporary MAPs get lower attention by Pakistan's SMEs.

In brief, results conclude that textile sector of Pakistan's SMEs makes wide use of past MAPs and only use selective modern practices. Adoption of these MAPs is highly affected by qualified staff of the firm. Size of organization is the important factor in adoption of MAPs. Larger firms can handle their complex operations because they have larger resources to adopt MAP and these firms employ new MAPs because they have highly qualified accountants and resources to give training (see Chenhall and Langfield-Smith, 1998 and Abdel-Kader and Luther, 2008). Results of this study are also coherent with previous studies on MAPs in developing countries (Ahmad, 2015; Karanja, 2014; Joshi, 2001; Phadoongsitthi, 2003; and El-Ebaishi et al., 2003).

The analyses of result suggest that adoption of MAPs were affected by several factors. This study revealed that the textile sector of SMEs of Pakistan is more affected by contingent factors such as size of the firm, competition, organization's structure and environment in which it operates. As such respondents argue that MAPs is much more helpful in planning, controlling, evaluating performance and in decision making. So it is necessary to adopt MAPs as size of firm increases. Competition is the important factor that influencing the choice of MAPs.

One of the factors that affect organizational structure is environmental uncertainty (Gull et al., 1994). As environmental uncertainty increases, organizations have to use more MAPs to deal with uncertainty. Firms that perceived low level of environmental uncertainty can easy predict market conditions and use low level of MAPs. Results indicate that the adoption of MAPs depends upon some contingent factor. These factors force out firms to adopt MAPs. Size of the firm, competition, organizational structure and environmental uncertainty have positively related with adoption of MAPs.

This study concludes specifically the benefits and problems on the adoption of MAPs. It is found that firms that use more MAPs do get perceived benefits. The firms that have low usage of MAPs are facing the problems of lack of training and skills and lack of resources. Moreover, the study concludes that MAPs act as supporting tool that increase overall performance of organization and helps SMEs to manage their resources to get firms objectives. It also revealed that MAPs helps management to effectively and efficiently manage organizations operations. 


\section{Implications}

It is necessary for SMEs to compete with global competition and market competitors. Although literature reviews the use of MAPs, and previous studies has pointed out on larger firms especially on developed countries, very little concern on SMEs in developing countries is witnessed. This study makes special contribution by giving knowledge of MAPs in SMEs of Pakistan. The research is distinctive not only because it addresses the extent of use of MAPs in the SMEs of Pakistan especially in Multan; but it also underscores factors that affect the adoption of MAPs, and examines benefits and problems in adopting MAPs in SME sector.

This study focus on a wide range of MAPs instead of limited set of MA practices. In this study contingency theory use as a foundation that shedding the light on factors affect the usage of MAPs in SMEs in developing countries. The findings conclude that MAPs are influenced by internal as well as external factors and these factors are significant continence variables in small business (Ahmad, 2015). This research thus contributes towards the gap of MAPs in SMEs in Pakistan and provides increased knowledge in SMEs context. Pakistan strived more as a developing country to compete with developed economies, and policy-makers can get that research useful to find relevant knowledge to enhance the performance of Pakistani SMEs.

This research may be a beginning point for further study of investigation of MAPs among SMEs in Pakistan and promote Pakistani researchers' interest to use SMEs sector as a sample. In particular it is expected that the Pakistani government will give more attention towards MAPs in SMEs and improve existing training programmes on the use of traditional and contemporary MAPs for the accountants.

\section{Limitations of The Study}

The study has the several limitations. First, this study only focused on one sector (textile sector) of Multan as a sample in Pakistan. The reason for the selection of Multan's SMEs can be due to the shortage of time and limited resources. The second limitation is that the low response to the questionnaire survey to acknowledge the extent of use of MAPs and this cannot be avoided and relatively small numbers of SMEs participated. More sectors and SMEs might be studied for increasing the generalizability of study.

Lastly, low response may be due to the complex structure of questionnaire on the extent of use of MAPs with Yes or No and Likert scale questions. It is possible that the respondent may have not understood the question and misinterpreted it. This limitation was minimized by ensuring that questionnaires were filled by high executives and accounting managers.

Beside these limitations, this study successfully fill the gap by responding to the need of research on adoption of MAPs in SMEs in developing countries and gives evidence of the use of MAP by Pakistani SMEs with additional contribution on the factors that influence the use of MAPs in Pakistani SMEs and benefits and problems on the use of MAPs in SMEs.

\section{Recommendations for Future Research}

The results of this study have several extensions of future research. First, the sample sized can be increased by adding further sectors in population. Second, case study approach other than interviews might be adopted to highlight the reasons for the adoption of MAPs in a more detailed to know how and why MAPs are adopted and not adopted. Third, there is need to investigate further the dependence of firms on past and contemporary MAPs. Fourth, with increasing global competition, economies needed to expand survey on the change of MAPs in more detailed way. Lastly, a comparative study might be conducted in Pakistan and compared it with another developing country in terms to explore cultural differences and contingent factors.

\section{References}

Abdel-Kader, M and Luther, R. (2004). An Empirical Investigation of the Evolution of Management Accounting Practices . Working paper No.04/06. pp.1-25.

Abdel-Kader, M., \&amp; Luther, R. (2008). The impact of firm characteristics on management accounting practices:A UK-based empirical analysis. The British

Accounting Review, 40, 2-27. http://dx.doi.org/10.1016/j.bar.2007.11.003

Abdel-Maksoud, A., Asada, T. and Nakagawa, M. (2008). Performance measures, managerial practices and manufacturing technologies in Japanese manufacturing firms: state-of-the-art. International Journal 
Business Performance Management, vol. 10, no. 1.

Abdul Rahman, I.K., Abdul Rahman, A.Z., Tew, Y.H. and Omar, N. (1998), “A survey on management accounting practices in Malaysian manufacturing companies”, Management Accounting Practices Paper 3, Concurrent session IC,

International Management Accounting Conference, National University of Malaysia, Selangor.

Amat, J., S. Carmona, and H. Roberts. 1994. Context and change in management accounting systems: A Spanish case study. Management Accounting Research 5 (2): 107-122.

Ashfaq.K (2012). Traditional Vs. Contemporary Management Accounting Practices and its Role and Usage across Business Life Cycle Stages: Evidence from Pakistani Financial Sector. Vol. 4, No.4, pp.104-125

Baldvinsdottir, G., Burns, J., NA Erreklit, H., \&amp;Scapens,R.,"The management accountant' s role," Financial Management, 2009, Jul/Aug,34

Burns, J., and R. W. Scapens. 2000. Conceptualizing management accounting change: An institutional framework. Management Accounting Research 11 (1):3-25.

Chenhall, R. H., \&amp;Langfield-Smith, K. (1998). Adoption and benefits of management accounting practices: An Australian study. Management Accounting Research, 9, 1-19. http://dx.doi.org/10.1006/mare.1997.0060

CIMA (2013) Management Accounting Practices of (UK) Small Medium-Sized Enterprises (SMEs).Improving SME performance through Management Accounting Education, Volume 9, Issue 4.

Doan Ngoc Phi Anh Duc-Tho Nguyen Lokman Mia, (2011),\&quot;Western management accounting practices in Vietnamese enterprises\&quot; Pacific Accounting Review, Vol.23 Issue 2 pp. $142-164$

Drury, C., Braund, S., Osborne, P. and Tayles, M. (1993). A survey of management accounting practices in UK manufacturing companies, Chartered Association of Certified Accountants.

Dyer, L.M. and Ross, C.A. (2007), “Advising the small business client”, International Small Business Journal, Vol. 25 No. 2, pp. 130-151.

Ferreira, A. (2002). Management accounting and control systems design and use: An Exploratory study in Portugal. $\mathrm{PhD}$ thesis. The Management School, Lancaster University, Lancaster.

Foster, G., and S. M. Young. 1997. Frontiers of management accounting research. Journal of Management Accounting Research 9: 63-77.

Ghosh, B.C. and Chan, Y.K. (1996), "Management accounting practices in Singapore: the state-of-the-art", unpublished manuscript, Nanyang Business School, Singapore

Guilding, C., Cravens, K.S. and Tayles, M. (2000). An international comparison of strategic management accounting practices. Management Accounting Research, vol.11, pp.113-135.

Hall, M. (2008). The effect of comprehensive performance measurement systems on role clarity, psychological empowerment and managerial performance. Accounting,Organizations and Society, vol. 33, pp. 141163.

Henri C. Dekker (2016). On the boundaries between intra-firm and interfirm management accounting research; Management Accounting Research 31 86-99

Hermes, N., Smid, P. and Yao, L. (2007). Capital budgeting practices: A comparative study of the Netherlands and China. International Business Review, vol. 16, pp. 630-654.

Hopper, T. (2000), "Management accounting in less developed countries", CIMA ResearchUpdate, Autumn/Winter, pp. 6-7.

Hopper, T., Koga, T., \&amp;Goto, J. (1999). Cost accounting in small and medium sized Japanese companies: An

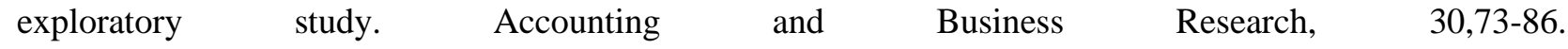
http://dx.doi.org/10.1080/00014788.1999.9728925

Hoque, Z. and James, W. (2000), "Linking balanced scorecard measures to size and market factors:impact on organisational performance", Journal of Management Accounting Research,Vol. 12, pp. 1-24.

Horngren, C.T., Datar, S., Foster, G., Rajan, M., and Ittner, C. (2009). Cost Accounting: A Managerial Emphasis. 13th edition, New Jersey, Upper Saddle River: Prentice Hall. 
Hudson, M., A. Smart, and M. Bourne. 2001. Theory and practice in SME performance measurement systems. International Journal of Operations \&amp; Production Management 21 (8): 1096-1115.

Hyvonen, J. (2007). Strategy, performance measurement techniques and information technology of the firm and their links to organizational performance. Management Accounting Research, vol. 18, pp. 343-366.

Innes, J. and Mitchell, F. (1995), “A survey of activity-based costing in the UK's largest companies", Management Accounting Research, Vol. 6 No. 2, pp. 137-153.

Islam, M. and Gowing, M. (2003), "Some empirical evidence of Chinese accounting system and business management practices from an ethical perspective", Journal of Business Ethics, Vol. 42, pp. 353-78.

Ittner, C., \&amp;Larcker, D. (2001). Assessing empirical search in managerial accounting: a value-based management perspective. Journal of Accounting andEconomics, 32: 349-410.

Ittner, C.D. and Larcker, D.F. (1998a.). Innovations in performance measurement: trends and research implications. Journal of Management Accounting Research, vol.6, pp. 205-238.

Johnson, T. H., and R. S. Kaplan. 1987. Relevance Lost: The Rise and fall of Management Accounting. Boston, MA: Harvard Business School.

Joshi, P.L. (2001), "The international diffusion of new management accounting practices: the case of India", Journal of International Accounting, Auditing and Taxation, Vol. 10, pp. 85-109.

Joshi, P.L. (2001). The international diffusion of new management accounting practices: the case of India. Journal of International Accounting, Auditing and Taxation, vol. 10, pp. 85-109.

Joshi, P.L., Al-Mudhaki,J. and Bremser, W.G. (2003). Corporate budget planning, control and performance evaluation in Bahrain. Managerial Auditing Journal, vol.18, no. 9, pp. 737-750.

Kaplan, R.S. (1984), “The evolution of management accounting”, The Accounting

Review, Vol. 59No. 3, pp. 390-418.

Lukka, K. and Granlund, M. (1996). Cost accounting in Finland: current practice

and trends of development. The European Accounting Review, vol. 5, pp.1-28.

Luther, R.G. and Longden, T. (2001), "Management accounting in companies

adapting to structural change and volatility in transition economies: a South African

study", Management Accounting Research, Vol. 12 No. 3, pp. 299-320.

Massey, C., Auld, T., Lewis, K., Perry, M., Walker, R. and Warriner, V.(2005), Micro by Name, Medium by Nature: A Report on an Investigation into Business Excellence \&amp; New Zealand Micro-enterprises, New Zealand Centre for Small and Medium Enterprise Research, Massey University, Auckland.

Ndwiga N. M (2011), The Role of Management Accounting in Creating and Sustaining Competitive Advantage: A

Case Study of Equity Bank, Kenya.

Otley, D.T. (1980), “The contingency theory of management accounting:

achievement andprognosis", Accounting, Organizations and Society, Vol. 5 No. 4, pp. 413-428.

Quinn, M. 2011. Routines in management accounting research: Further

exploration. Journal of Accounting \&amp; Organizational Change 7 (4): 337-357.

Saeed, K. A. (1993). A global perspective of accounting education and certification process: A chapter with focuson Pakistan. New York7 Pergamon Press.

Speckbacher, G., Bischof, J. and Pfeiffer, T. (2003). A descriptive analysis on the implementation of Balanced Scorecards in German-speaking countries, Management Accounting Research, vol. 14, pp. 361-387.

Sulaiman, M. Ahmad, N.A.N. and Alwi, N. (2004). Management accounting

practices in selected Asian countries. Managerial Auditing Journal, vol. 19, no.4, pp. 493-508.

Sulaiman, M., Nik Ahmad, N.N., Alwi, N. (2002), "Management accounting

practices in Malaysia: a survey of the industrial and consumer products sectors",

unpublished research report, International Islamic University, Kuala Lumpur,

Malaysia.

Sulaiman, S. and Mitchell, F. (2005). Using a typology of management 
accounting change: An empirical analysis. Management Accounting Research, vol.16, no. 4, pp. 422-437.

Szychta, A. (2002). The scope of application of management accounting methods in Polish enterprises Management Accounting Research, vol.13, pp. 401- 418.

Talha, M. et al. (2010), A New Look At Management Accounting, The Journal of Applied Business Research July/August 2010 Volume 26, Number 4.

TeemuMalmia, (2016). Managerialist studies in management accounting: 1990-2014, Management Accounting Research 31-44

$\mathrm{Wu}$, J., Boateng, A. and Drury, C. (2007), "An analysis of the adoption, perceived benefits, and expected future emphasis of western management accounting practices in Chinese SOEs and JVs", The International Journal of Accounting, Vol. 42 No. 2, pp. 171-85. 
